\title{
Persistence as a function of locus of control and Expectancy of goal attainment
}

\author{
Dr. Rekha Sharma \\ Associate professor, National Govt. College, Sirsa
}

\begin{abstract}
Rotter's scale of locus of control and experimentally induced situations of probability of success by giving specific instructions. An Insoluble figure--'perceptual reasoning task' was used to test persistence of externally controlled Ss \& internally controlled Ss in three experimental conditions i.e.P.25 (difficult task), P.50(intermediate task) \&P.75(easy task).Persistence scores were taken as time spent by Ss on perceptual reasoning task. Analysis of variance \& $t$-test were used for analysis of data. Findings concluded that-----(1) internally controlled Ss persisted longer at P.50\&P.75 in comparison to P.25.(2) externally controlled Ss persisted longer at P.50 in comparison to P.25\&P.75(3)there was no significant difference between internally controlled Ss and externally controlled Ss at P.50.
\end{abstract}

Keywords: Persistence, Locus of control, External locus of control, internal locus of control, probability of success, P.25, P.50\&P.75.

\section{Introduction}

Atkinson developed a risk taking model of an Achievement that itself is in a way union of several "Expectancy" theories. These theories lay stress on multiplication relationships among motive, expectancy \& incentive variables. This theory assumes that motive to achieve, the expectancy or probability of success (Ps) and the incentive value of success (Is) determine the effort expenditure or persistence and the strength of the tendency to achieve a task. Further, Atkinson is of the opinion that an individual in an achievement oriented situation who has to choose a task at certain level of difficulty finds himself in a conflicting situation involving the two tendencies i.e. the tendency to seek success (Ts) and the tendency to avoid failure $\left(\mathrm{T}_{\mathrm{AF}}\right)$. Atkinson gave two equations to define $\mathrm{Ts} \& \mathrm{~T} \mathrm{AF}$.

1. $\quad$ Ts $=$ Ms $\mathrm{x}$ Ps $\mathrm{x}$ Is

Ms - Motive to achieve success.

Ps - Subjective probability of success (or Ss expectancy to attain goal).

Is - Incentive value of success.

2. $\quad \mathrm{T}_{\mathrm{AF}}=\mathrm{M}_{\mathrm{AF}} \times \mathrm{P}_{\mathrm{f}} \times \mathrm{I}_{\mathrm{f}}$

$\mathrm{M}_{\mathrm{AF}}$ - Motive to avoid failure.

$\mathrm{P}_{\mathrm{f}}-$ Subjective probability of failure.

$\mathrm{I}_{\mathrm{f}}$ - Incentive value of failure.

Ts is the product of interaction between Ms, Ps \& Is whereas $\mathrm{T}_{\mathrm{AF}}$ is the product of interaction between $\mathrm{M}_{\mathrm{AF}}, \mathrm{P}_{\mathrm{f}}$ $\& \mathrm{I}_{\mathrm{f}}$.

Atkinson assumed that all persons have both Ms and MAF. The total motivational tendency or resultant tendency is assumed to equal the combined effects of Ts \& $\mathrm{T}_{\mathrm{AF}}$.

$\mathrm{T}=\mathrm{Ts}-(-\mathrm{TAF})$ or $\mathrm{Ts}+\mathrm{T}_{\mathrm{AF}}$

Or

$\mathrm{T}=(\mathrm{Ms} \times \mathrm{Ps} \times \mathrm{Is})+\left(\mathrm{M}_{\mathrm{AF}} \times \mathrm{P}_{\mathrm{f}} \times \mathrm{I}_{\mathrm{f}}\right)$

We can express it in another way: $T=\left(\mathrm{Ms}-\mathrm{M}_{\mathrm{AF}}\right) \times\left(\mathrm{P}_{\mathrm{f}} \times \mathrm{I}_{\mathrm{f}}\right)$.

Ms- $\mathrm{M}_{\mathrm{AF}}$ tells us whether a person will approach or will avoid an achievement situation. Atkinson in his theory explained that persons having $\mathrm{Ms}>\mathrm{M}_{\mathrm{AF}}$ have greater persistence at task having Ps 50 whereas person having $\mathrm{M}_{\mathrm{AF}}>$ Ms have greater persistence at task having Ps 25 or Ps 75 . This theory has adopted the strategy of studying simultaneously attributes of personality and immediate environmental influence or situational cognition that are represented by specific expectancies in terms of easy or difficult task. Here, we cannot ignore the after abiding effects of the past success and further experiences that manifest themselves in the form of generalized expectancies as locus of control dimension of personality. No doubt specific expectancies of internal reinforcement (where people perceive connection between behavior and performance also called Internally Controlled) and external reinforcement (where people perceive reinforcement as a result of luck or chance also called externally controlled) too can have impact on achievement behavior especially in novel situations like the 
one in problem solving \& perceptual reasoning task that is being employed in the present study to assess the persistence. Russell et al (1979) define expectancy as a belief about the further performance on the basis of the past experiences. LOC (Generalized expectancy) based on antecedent factors like success or failure experiences as such cannot remain dormant or passive in that challenging novel situation but in all probability is likely to influence the behavior. Rotter proposes an equation:

$\mathrm{Es}_{1}=\mathrm{f}\left(\mathrm{Ds}_{1}+\mathrm{GE}\right)$

The equation conveys that the expectancy of reinforcement in situation I (ESI) is determined on the basis of expectancies in that particular situation, as well as by generalized expectances (GE) from similar situation. The more novel a situation the greater the importance of generalized expectancies in determining immediate beliefs. On the other hand given a great deal of experience in a specific situation generalized expectancies may have little significance influencing behavior Weiner (1985) called it as "problem solving" generalized expectancy. He explained the concept 'LOC' as a belief that a response will or will not influence the attainment of a goal. Therefore we can't ignore it as a determinant of the expectancy concerning a particular type of goal. He further explained that perceived LOC is believed to influence the specific goal expectancy in any given situation with the extent of the influence in part dependent upon the novelty and the ambiguity of the settings as well as the degree of reinforcement that the individual has directly experienced in that setting. Differentiating between the respective roles of specific and generalized expectancies Lefcourt et al, 1969; phares 1976 remark that specific expectancies related to a success probability, at a task may be playing a meditational role between an individual's generalized expectancy and resultant behaviors. Recently researches are more focused on Academic achievement instead of $\mathrm{n}$-achievement. Academic achievement is a term usually used to mean an individual's performance in Ss taught \& tested in schools \& colleges. This has always been the concern of educationists as well as potential researchers in educational psychology. According to Nenty (1986), achievement is a function of personal as well as environmental factors, an individual tends to naively attribute his/her behavior of the level of performances more to one, then the other of these factors where there is an internal motivated factors (beliefs in one's ability) towards the goal and individual's level of performance (persistence) increases. Interest has also specific impact in the maintenance (persistence) of effort for goal. If it decreases even through persons are internally controlled start declaiming their performance.

It is found that whether it is N-Achievement or academic achievement, they develop \& grow in schools during the age of adolescence. LOC is considered as belief and it is learnt through socialization by parents, teachers, role-models. Being a psychological construct, LOC has been focused by the researchers and have been reviewed by them (Lefcourt 1982, Nijus \& Brockway, 1999, Tella \& Tella, 2005 \& Yates, 2009).LOC is a psychological variable, which refers to the extent to which a person feels he has control over his destiny. The feeling of control here can be conceived to be spread out along a continuum. At one end, the internal control connotes the attitude that one can manipulate his environment by means his potential efforts or skills. On the other end of the continuum, the external control consists of a self attitude characterized by the feeling that all that happen to a person is the consequence of chance luck, fate and several other like factors which are beyond one is control. Kutanis (2010) \& Sargat (2001) confirmed that individual with external LOC relate success or failure not related to them and attribute success to backing and base failure upon environmental factors.

Students in schools and collages based on this concept perceive differently as a result of their control. Internally controlled students see failure as his own inadequacy and put more efforts (greater persistence) for getting success. But the picture is different for externally controlled students who belief in luck \& chance. They put their efforts (greater persistence) when the situation is simply or very tuff in the hope that perhaps the luck will favour them. If not, they do not blame themselves. Discussion above said concludes that internal controlled students being potential oriented (Ms $>\mathrm{MAF}$ ) do not want to face failure, so they persist longer in any situation where as externals being luck \& chance oriented (Ms $>\mathrm{MAF}$ ) do not have fear of failure so they persist for success in the hope that perhaps luck will smile on them. Is this the real situation in adolescents? The researcher wanted to study the effect of LOC \& Probability of success/failure on the persistence of students.

Objectives: To find out the role of Locus of control at various levels of Expectancy of goal attainment among male adolescents.

\section{Rational of the Study:}

Adolescence is the age of development especially in cognition \& affection. Their development is influenced mainly by socialization. Role model, behavior of Parents \& Teachers, knowledge given by Teachers \& Parents, Role of Social media etc., shape their personality \& confidence in them about their potentialities \& skills. Such factors make them different from each other in getting success / failure and their attitude for them and also their future behavior course regarding their goal attainment. Researcher wanted to study the effect of LOC \& probability or expectancy of goal attainment on the persistent efforts given by the students in an 
experimental situation where she used an insolvable problem - "A perceptual reasoning task", to see the picture of findings whether they are in the same line as explained by earlier researchers or the scene is different.

\section{Hypotheses:}

- Internally controlled subjects would persist longer at P.50 in comparison to Externally controlled subjects.

- Externally controlled subjects would persist longer at Ps.75 in comparison to Internally controlled subjects.

- There would be no difference at Ps.25 among internally controlled subjects as well externally controlled subjects.

\section{Research Design:}

\section{Methodology:}

$2 \times 3$ factorial design was used to asses persistence at a perceptual reasoning task test as a dependent variable when independent variables were LOC (External \& Internal LOC) and probability of success (Ps.25, Ps.50 \& Ps.75).

\section{Sample:}

The sample was consisted of 180 male students $(10+1 \& 10+2$ class $)$ of various Govt. Schools of Karnal. They were selected randomly from the attendance registers of the Science, Arts \& Commerce Classes. Age range was 15 to 18 Years.

\section{Tools \& Procedure:}

After getting permission from the head of the institutions, tools were applied on the sample. The following tools \& procedure were adopted------

\section{LOC:}

For getting data on LOC, Rotter's LOC scale was administered to each Student. The scale was scored on the dimension of LOC. Extreme groups (Internally controlled Students \& externally controlled Students) were identified on the basis of mean \& 1SD. Students with mean + ISD \& above were considered as externally controlled students whereas meant - ISD \& below were considered internally controlled students.

\section{Probability of success (Ps):}

This was done by inducing different instructions to the two groups of Students who were internally \& externally controlled.

Ps.25- For developing probability of Ps.25 the following instructions were given:

"This is very difficult task. The probability of success is .25 i.e. only 25 out of 100 did it successfully in previous tests. Please try to solve it. You can take as many trials as you want."

Ps.50- For developing Ps.50 the following instructions were given to the students:

"This is a difficult task, but not very much. 50\% students did it successfully in previous tests. Please try to solve it and take as many trials as you want.

Ps.75- For developing Ps.75 the following instructions were given to the students:

"This is very easy task. Approximately 3 out of 4 students did it successfully on previous tests. Please try to solve it and take as many trials as you want.

\section{Perceptual Reasoning Task Test}

It was used to get persistence scores of the students in various experimental conditions. The task was a line diagram approximately 1.5 inch square (given below) printed on a white paper. It was an 'insoluble figure' and was used to assess persistence in terms of time score (How much time he took in solving the problem).

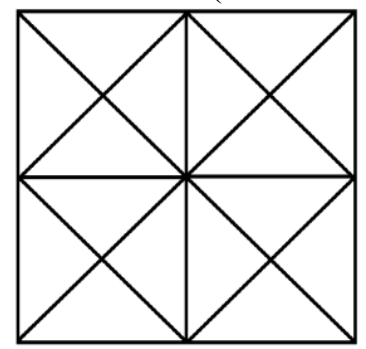


Students were instructed as below:

"You have to make the diagram shown to you with pen/pencil according to following rules:

1. You will not be permitted to left his pen/pencil from the figure once You started to make it;

2. You will not be permitted to trace over any line twice."

3. You can take as much trials as you want.

This test was presented to all students in the individual sessions. Time taken by the subject was considered as their scores on the persistence.

Research Paradigm with the distribution of students:

\begin{tabular}{|l|l|l|l|}
\hline \multirow{2}{*}{ Probabilityof success (Ps) } & \multicolumn{2}{|c|}{ Locus of Control } & \multirow{2}{*}{ N } \\
\cline { 2 - 3 } & Internal LOC & External LOC & \\
\hline Ps.25 & 30 & 30 & 60 \\
\hline Ps.50 & 30 & 30 & 60 \\
\hline Ps.75 & 30 & 30 & 60 \\
\hline N & 90 & 90 & 180 \\
\hline
\end{tabular}

\section{Analysis of Data:}

After getting tested on test of homogeneity by Hartley's test of F.max i.e.value of F.max insignificant (sample as homogenous) scores on the various experimental conditions were analyzed by $2 \times 3$ analysis of variance. These were shown in table no. I. Significant values were further tested by applying ' $t$ ' test and respective results were analyzed with reference to previous findings.

Table-I Summary Table of ANOVA (2x3) between Loc, Ps \& Loc x Ps (N=180) Between Loc, Ps $\&$ Loc $x$ Ps (N:180)

\begin{tabular}{|l|l|l|l|l|}
\hline Source of Variation & Sum of Square & df & Ms & F \\
\hline Ps & 1509.23 & 2 & 665.135 & 60.47 * \\
\hline Loc & 39.36 & 1 & 39.36 & - \\
\hline Ps x Loc & 701.41 & 2 & 309.43 & $28.13^{*}$ \\
\hline $\begin{array}{l}\text { Error within } \\
\text { Treatment }\end{array}$ & 1914 & 174 & 11 & - \\
\hline
\end{tabular}

* Significant at .01 level.

Table -I showed significant value of Ps and interactional effect of Ps \& Loc at .01 level. To get more specific picture' $t$ ' test was used pair wise at different levels of Ps. This was shown at Table-II.

Table - II Pairwise comparison of Means at different levels of $\mathrm{Ps}(\mathrm{n}=60)$

\begin{tabular}{|c|c|c|c|c|c|c|}
\hline Levels & Means & Pair & Diff. & SEdm & 't' & $\begin{array}{c}\text { Level of } \\
\text { significance }\end{array}$ \\
\hline Ps .25 & 14.96 & Ps 25, Ps .50 & -4.86 & .42 & 11.57 & .01 \\
\hline Ps .50 & 19.82 & Ps 25, Ps .75 & -3.15 & & 7.5 & .01 \\
\hline Ps .75 & 18.11 & Ps 50, Ps .75 & 1.71 & & 4.07 & .05 \\
\hline
\end{tabular}

Table -II showed that differences between Ps $.25 \&$ Ps .50 \& Ps $.25 \&$ Ps. 75 were significant at .01 where as difference between PS $.50 \&$ Ps .75 was significant at .05 .

Result shown in Table -II reflected that in comparison to Ps .25 (difficult task or lesser probability of success) Ps .50 (moderate difficult task or 50\%-50\% of probability of success or failure) had greater significant mean (P. $25<$ Ps .50 at .01). It showed that when the task had moderate difficulty level and had equal chance of success \& failure, Ss showed greater persistence to attain the goal. Further, in comparison to Ps 25 (difficult task) Ps .75 (easy task or greater probability of success) had greater significant mean (Ps .25< Ps .75 at .01). It showed that subjects persisted longer when the task was easy in comparison to when the task was difficult. Again when we compared Ss on easy task (Ps.75) and moderate difficulty task (Ps.50) the mean of Ps.50 (moderate difficult task) was significantly greater than mean of Ps .75 (easy task)i.e. (Ps .50>Ps .75 at .05)

Table -III Interaction between Ps x Loc

\begin{tabular}{|c|c|c|}
\hline Ps & Internal Loc & External Loc \\
\hline .25 & 13.42 & 16.5 \\
\hline .30 & 20.61 & 19.03 \\
\hline .75 & 19.84 & 16.39 \\
\hline
\end{tabular}


Table -IV Pairwise comparison of means of Ps and Loc

\begin{tabular}{|c|c|c|c|c|c|c|}
\hline $\begin{array}{l}\text { Levels Probability } \\
\text { of Sncceo }\end{array}$ & Means & Pair & Diff. & SEdm & $\mathrm{t}$ & Significant level \\
\hline Ps .25 & $13.42,16.5$ & ILoc, ELoc & -3.08 & .84 & 3.67 & .01 \\
\hline Ps .50 & $20.61,19.03$ & ILoc, ELoc & 1.58 & & 1.89 & - \\
\hline Ps.75 & $19.84,16.39$ & ILoc, ELoc & 3.45 & & 4.10 & .01 \\
\hline \multicolumn{7}{|l|}{ Internal Loc } \\
\hline Ps. 25 & $13.42,20.61$ & Ps .25, Ps .50 & -7.19 & .84 & 8.50 & .01 \\
\hline Ps .50 & $13.42,19.84$ & Ps .25, Ps . 75 & -6.42 & & 7.64 & .01 \\
\hline Ps.75 & $20.61,19.84$ & Ps .50, Ps. 75 & .77 & & .92 & - \\
\hline \multicolumn{7}{|l|}{ External Loc } \\
\hline Ps .25 & $16.5,19.03$ & Ps .25 , Ps .50 & -2.53 & .84 & 3.01 & .01 \\
\hline Ps .50 & $16.5,16.39$ & Ps .25 , Ps . 75 & .11 & & .13 & - \\
\hline Ps .75 & $19.03,16.39$ & Ps .50, Ps .75 & 2.64 & & 3.14 & .01 \\
\hline
\end{tabular}

Obtained results were shown in the graph reflect almost same pattern for ELoc Ss \& ILoc Ss at various levels of Ps i.e. Ps .25, Ps .50 \& Ps .75.

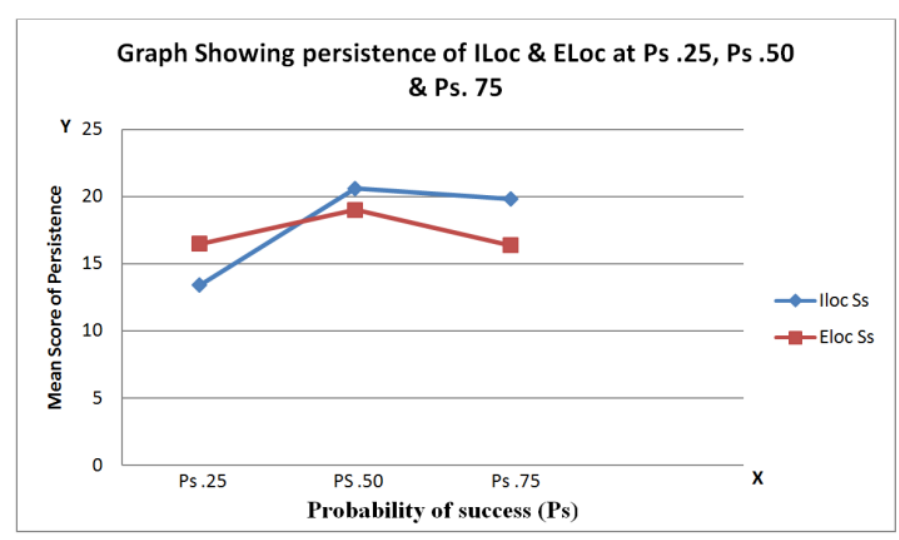

Table IV and graph showed that ILoc Ss were more persistent at Ps .50, i.e. Internal controlled Ss who believed in their ability showed greater persistence in performing the experimental task (solving the problem) in comparison to External Loc Ss (mean 20.61 > 19.03) but this difference was not found significant. Further, the table and graph both showed that ELoc Ss Showed significant greater persistence at Ps .25 in comparison to I Loc Ss $(13.42<16.5$ at .01$)$. It might be due to that ELoc Ss believed in luck or external factors and the task was very difficult, so they persisted longer and explained their failure to themselves due to luck. Their failure was not due to their less ability but due to luck or external factors. When Ps .75 was compared, it was found that there was significant difference between ELoc Ss \& ILoc Ss. ILoc Ss did better in comparison to ELoc Ss (19.84>16.39 at .01).Internal Loc Ss persisted longer to solve the problem as they believed in their ability and failure at an easy task (Ps.75) was "shame" for themselves, so they persisted longer in comparison to E Locs who believed in luck or role of external factors. The graph showed almost similar pattern of persistence at various probability levels by ILocs \& ELocs i.e. greater persistence at Ps.50 in comparison Ps. 25 \& Ps. 75.

The same results were more clearly shown in different way by bar diagram.

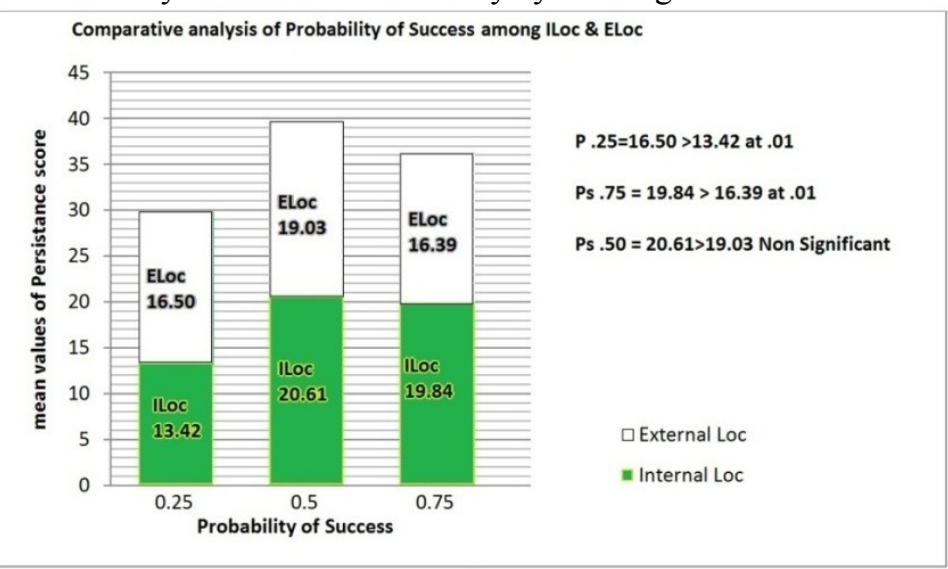

Both graphs concluded a same trend. 


\begin{tabular}{|} 
Table- V Summary of results \\
\begin{tabular}{|c|c|c|c|c|}
\hline \multirow{2}{*}{ Sr. No. } & Variables & \multicolumn{3}{|c|}{ Levels of Ps } \\
\cline { 2 - 5 } & & $.25-.50$ & $.50-.75$ & $.25-.75$ \\
\hline 1 & General Trend & $.25<.50$ & $.50=.75$ & $.25<.75$ \\
\hline 2 & External LOC & $.25<.50$ & $.50>.75$ & $.25=.75$ \\
\hline 3 & Internal LOC & $.25<.50$ & $.50=.75$ & $.25<.75$ \\
\hline
\end{tabular}
\end{tabular}

\section{Discussion}

Statistical analysis of the obtained results did not provide clear cut picture about the interactive role of Locus of Control and Probability of success (Expectancy of goal-attainment). Locus of control (Loc) did not show significant effect while Probability of success did it significantly more important. There interaction showed significant effect. Loc was a generalized Expectancy where as Probability of Success (Ps) being situational variable was treated as specific expectancy. Probability of success was defined, here by taskdifficulty eg. Ps. 25 (Difficulty task), Ps.50 (modulate difficult task or neither easy nor difficult) \& Ps. 75 (easy task). In this experimental situation where probability of success was uncertain, subjects had to depend upon generalized expectancies (E-I Loc). Stipei \& Weisz (1981) found a strong relationship between Loc \& nAchievement among school boys and Rana, Muammer \& Zeynap (2011) found that students generally have internal Loc as they usually work hard (n-Ach) to get success or their goal. But in this study Loc \& persistence (n-Ach) did not show significant relationship and surprisingly showed significant effect when it interacted with Probability of success (Ps).

Further analysis by t-test revealed some other important findings about relationship of Loc \& Ps:

Externally controlled $\mathrm{S}_{\mathrm{S}}$ and Internally Controlled $\mathrm{S}_{\mathrm{s}}$ persisted equally at Ps.50 (modulate difficulty task) and both did not differ significantly. Why did it happen? A task at Ps.50 i.e. 50-50 chances of success or failure presented a risky situation which was characterized by 'uncertainty'. Trope (1979), Sorrentino \& H Evitt (1984) considered such task which was further dominated by 'challenge' because the task here did not provide any situational clue about chances of success or failure. 'Challenge' means the potentiality to grow, mastery or some type of gain. The appraisal of the situation as challenging is always dependent upon the situational and personal factors. Here, problem-solving was presented to the Ss with the s9tuation having $50 \%$ chances of success \& 50\% chances of failure. In such situation Ss could prove themselves. Lazarus (1959) explained this situation: Ss started solving the problem and meantime they developed positive emotions (excitement, hopefulness). These emotions provided them motivational support for problem solving behavior and as a result greater efforts were generated at Ps.50 irrespective of their beliefs regarding behavioral outcome i.e. internal Loc and external Loc.

At Ps.50, the outcome of the task was most influenced by efforts therefore Internally controlled Ss (I-Loc) who believed in their ability put maximum efforts to get the goal, so they persisted longer. Basin \& Sesen (2006) found that internally controlled Ss performed high n-Achievement and this was supported by Rana, Zeynap \& Muammer (2011) that students generally have Internal Loc which made them hard worker.

Previous findings revealed that Internally controlled Ss persisted longer in comparison to Externally controlled Ss. Nenty (1986) confirmed that externally controlled Ss attributed their success or failure to luck or difficulty level of the task sarget (2001) \& Kutanis (2010) confirmed that ELoc subjects related their success to luck and failure upon environmental factors. Nenty (19086) further concluded that E Loc Ss performed significantly less than internal Loc Ss.

Interestingly, here we did not find the same results. Here, both, internal as well as external controlled Ss persisted equally longer at Ps.50.

Now, the research argued that as the task was neither easy nor difficult, externally controlled Ss felt less pressure and negativity of the situation generated by the task having intermediate difficulty level. Chance \& luck were unstable and uncontrollable factors, therefore, Ss believed or hopeful that just next trial on the task might bring the good fortune for them. 'Gambler's fallacy' - every failure on the task might be strengthing their expectation for success in next trial, resulted greater persistence at Ps.50 among externally controlled Ss.

In another experimental situation i.e. Ps.25 (difficult task) Ss had very low probability of success (i.e. 25 out of 100 chances). In this situation, failure was more prominent than success. These specific expectancies made the task uncontrollable. The unsolvable task was used for experimentation; therefore, failure at every attempt confirmed the difficulty level of the task. Because the task was uncontrollable therefore ability \& efforts were proved non-productive. It made the situation 'dangerous'. General orientation of Ss in this situation would be to leave the task early. Internally controlled Ss who were ability oriented left the task early as predicted by general orientation of Ss. Internally controlled Ss did show much persistence in solving the problem because they know that there was greater chances of failure (task was beyond their capacity) therefore failure at initial efforts made them to leave the task early.

Surprisingly, externally controlled Ss persisted significantly longer than internals at Ps.25. It was a confusing picture of results. It might be due to their Locus of control which motivated them to exert more efforts 
in such dangerous situation with the hope that luck would smile on them and to succeed on difficult task gave them social recognition as "Winner".

In another experimental situation Ss were confronted with a task of Ps. 75 which was supposed to be easy task. Failure at easy task was very shameful or humiliating for those who believed in themselves (I-Loc). To avoid such humiliation, ability oriented Ss i.e. internally controlled Ss persisted longer in comparison to externally controlled Ss. Why externally controlled Ss persisted lesser at an easy task (Ps.75). The Ss believed in luck \& chance and failure at an easy task in the initial efforts attributed "Bad luck" or "Bad Day" by them. So, they left the task earlier.

There is a summary of findings.

1. General trend of Ss showed that they persisted longer at Ps.50 in comparison to Ps.25. They persisted longer at Ps. 75 in comparison to Ps.25. They showed equal persistence at Ps. 50 \& Ps. 75.

2. Internal Loc Ss behaved first like the general trend of Ss i.e. greater persistence at Ps.50 7 Ps.75, lesser persistence at Ps. 25 and equal persistence at Ps. 50 \& Ps. 75.

3. External Loc Ss behaved somewhat differently. They persisted longer at Ps. 50 in comparison to Ps. 25 \& Ps.75. They showed equal persistence at Ps. 25 \& Ps. 75 (did not differ significantly between easy \& difficult task).

In this study, externals behaved differently, not accordingly to the previous findings. Here, the researcher support the concept of 'Bi-Local Expectancy' and Loc as un-dimensional scale as proposed by Torun \& April (2006). 'Bio-Local Expectancy' is a concept which believed that every person has both Locus of control- internal Locus of control as well external Locus of control. The role of Locus of control as 'Bi-local expectancy' and specific expectancies like task-difficulty yet has to be found out. The role of cognitive contributions and affective factors would be needed to identified $\&$ verified by the researchers.

\section{Conclusion}

Based on the above findings, it could be concluded that Locus of control (internals as well as externals) affects every student's success or failure irrespective of the task-difficulty or Probability of success. Since Locus of control relates to both, uncertainty \& reality of life, the findings of this study collaborate the fact that Locus of control is significantly affecting the expectancy of goal attainment (Ps). It was proved by present findings internally controlled Ss persisted longer at Ps.50 and Ps.75 in comparison to externally controlled Ss persisted longer at Ps. 50 \& Ps. 25 in comparison to internals.

\section{Implication of the study}

The findings of this study have significant implications as they are giving a new picture of externally controlled Ss. No significant difference between externals and internals at Ps.50 when situational clues failed, is giving a point that Locus of control might be uni-dimensional instead of believing separate constructs as 'externals' \& 'internals', A support for 'Bi-local expectancy' is found in these4 findings. But, we cannot say it finally as more researchers are needed to conduct in this direction to give more new in the area of personality \& Social psychology.

\section{References}

[1] Atkinson, J.W. (1957). "Motivational determinants of risk-taking behavior". Psychological Review, 64, 359-372.

[2] Kutanis, R.O. (2010). Organizational culture (Lecturer notes) in R.O. Kutanis, M.Mesci \& Z.ordur (Eds). The effects of Locus of control on learning performance. Journal of Economics \& Social Studies 1(2), 113-133.

[3] Lefcourt, H.M. (1982) Locus of control (Inded) Hillsdale, NJ: Lawrence Erlbaum Associates in A. Angelika; H. John \& H.Richard, J.S.O. (Eds). Locus of control, Self-Efficacy and Motivation in different schools; Is Moderation the key of success? AU Educational Psychology. V.25(5) 517-535.

[4] Lefcourt, H.M. and Wine, J. (1969). "Internal v/s external control of reinforcement and the deployment of attention of experimental situations. Canadian Journal of Behavioral Sciences. 115, 153-160.

[5] Nenty, H.J. (1985). The effect of Performance Attribution on Attitude to study, Achievement motivation and Tendency to cheat in examination. The Profess of Education Vol. LIX, Pp 10-11.

[6] Njus, D.M. \& Brockway, J.H. (1999). Perceptim of competence and Locus of control for positive and negative outcomes. Personality and individual difference 26: 531-548.

[7] Pharas (1976). "Locus of control in personality" Morristown, N.J: General Learning Press.

[8] Rana, O.K.; Muammer, M. \& Zeynep, O (2011). The Effect of Locus of control on learning performance; A case study of an Academic organization. Journal of Economics \& Social studies. 1(2), 113-133.

[9] Russell et al (1979) "The cognition emotion process in achievement related context." Journal of personality and social Psychology, 37, 1211-1220.

[10] Sarget, S. (2001). Differentiation between cultural and management (2nd ed) in R.O. Kutanis M. Mesci \& Z. Ovdur (Ed.). The Effect of Locus of control an learning performance. Journal of Economics \& Social Studies. V. 1(2) 113-133.

[11] Sorrentino, R.M. and Hewitt, E.C. (1984). "The uncertainty- reducing properties of achievement tasks revisited". Journal of personality and Social Psychology, 47, 884-889.

[12] Stipei, D.J. \& Weisz, J.R. (1981) perceived personal control and Academic Achievement. In A. Anderson, H. John \& H. Richard J.S., O (Eds.) Locus of control; Self -Efficacy \& Motivation in Different schools; Is motivation the key to success? AUI Educational Psychology 25(5), 517-535 
[13] Tella, A. Jr. \& Tella, A. (2005). Locus of control and Self -Efficacy as determinant of Academic Achievement among Secondary School Students in Osun State Unity Schools in A. Tella, A, Tella \& O' Adeniyi (Eds) Locus of control, interest in schooling, selfefficacy \& Academic Achievement. Cypriot Journal of Educational Sciences. V 4 (1) 168-182.

[14] Torun \& April (2006) Rethinking individual control: Implications for business managers. Journal for Convergence, 7(1), 36-39.

[15] Trope, Y. (1979) "Un certainty-reducing properties of achievement tasks". Journal of personality and social psychology, 37, 15051518.

[16] Weiner (1985). "Human Motivation" Springer-Verlog, New York Inc.

[17] Yates, R. (2009). Locus of control and Academic achievement: A study of gender and grade level differences among low income African- American students in a middle school. Procenest dissertations and these university of Auckland, Newzealand. 